"This is the peer reviewed version of the following article: Quantum Chemical Study of the Mechanism of Water Oxidation Catalyzed by a Heterotrinuclear Ru2Mn Complex, which has been published in final form at:

https://onlinelibrary.wiley.com/doi/10.1002/cssc.201802395

This article may be used for non-commercial purposes in accordance with Wiley Terms and Conditions for Self-Archiving."

\title{
Quantum Chemical Study of the Mechanism of Water Oxidation Catalyzed by a Heterotrinuclear $\mathrm{Ru}_{2} \mathrm{Mn}$ Complex
}

Ying-Ying Lia, Carolina Gimbertb, Antoni Llobett ${ }^{b}$, Per E. M. Siegbahnc, Rong-Zhen Liao ${ }^{a *}$

aKey Laboratory of Material Chemistry for Energy Conversion and Storage, Ministry of Education, Hubei Key Laboratory of Bioinorganic Chemistry and Materia Medica, Hubei Key Laboratory of Materials Chemistry and Service Failure, School of Chemistry and Chemical Engineering, Huazhong University of Science and Technology, Wuhan 430074, China

bInstitute of Chemical Research of Catalonia (ICIQ-BIST), Avinguda Països Catalans 16, 43007 Tarragona, Spain

cDepartment of Organic Chemistry, Arrhenius Laboratory, Stockholm University, Stockholm 10691, Sweden

*Corresponding author: rongzhen@hust.edu.cn 


\begin{abstract}
The heterotrinuclear complex $\mathbf{A}\left\{\left[\mathrm{Ru}^{\mathrm{II}}\left(\mathrm{H}_{2} \mathrm{O}\right)(\operatorname{trpy})\right]_{2}\left(\mu-\left[\mathrm{Mn}^{\mathrm{II}}\left(\mathrm{H}_{2} \mathrm{O}\right)_{2}(\mathrm{bpp})_{2}\right]\right)\right\}^{4+}$ was disclosed to catalyze water oxidation both electrochemically and photochemically with $\left[\mathrm{Ru}(\text { bpy })_{3}\right]^{3+}$ as the photosensitizer and $\mathrm{Na}_{2} \mathrm{~S}_{2} \mathrm{O}_{8}$ as the electron acceptor in neutral phosphate buffer. The mechanism of water oxidation catalyzed by this unprecedented trinuclear complex was studied via density functional calculations. The calculations showed that a series of oxidation and deprotonation events take place from A, leading to the formation of complex 1 (formal oxidation state of $\mathrm{Ru} 1^{\mathrm{IV}} \mathrm{Mn}{ }^{\mathrm{III}} \mathrm{Ru} 2^{\mathrm{III}}$ ), which is the starting species for the catalytic cycle. Three sequential oxidations of 1 result in the generation of the catalytically competing species 4 (formal oxidation state of Ru1 ${ }^{\mathrm{IV}} \mathrm{Mn}^{\mathrm{V}} \mathrm{Ru} 2^{\mathrm{IV}}$ ) that triggers the $0-0$ bond formation. The direct coupling of two adjacent oxo ligands bound to $\mathrm{Ru}$ and $\mathrm{Mn}$ leads to the production of a superoxide intermediate Int1. This step was calculated to have a barrier of $7.2 \mathrm{kcal} \mathrm{mol}^{-1}$ at the B3LYP*-D3 level. Subsequent $\mathrm{O}_{2}$ release from Int1 turns out to be quite facile. Other possible pathways were found to be much less favorable, including water nucleophilic attack, the coupling of an oxo and a hydroxide, and the direct coupling pathway at a lower oxidation state $\left(\mathrm{Ru}^{\mathrm{IV}} \mathrm{Mn}^{\mathrm{IV}} \mathrm{Ru}^{\mathrm{IV}}\right)$.
\end{abstract}

Keywords: water oxidation; mechanism; density functional calculations; ruthenium; manganese; trinuclear. 


\section{Introduction}

A promising scheme to convert solar energy into chemical energy is the water splitting driven by sunlight. Water oxidation occurs at a potential of $1.23 \mathrm{~V}$ vs the standard hydrogen electrode (SHE) and is both thermodynamically and kinetically very unfavorable. In photosystem II, a $\mathrm{Mn}_{4} \mathrm{Ca}$ cluster in the oxygen evolution center (OEC) is known to catalyze the oxidation of water into molecular dioxygen..$^{1-5}$ During the past few decades, extraordinary efforts have been dedicated to the synthesis of manganese-based molecular complexes to mimic the structure and function of OEC.610 Other transition metals have also been used for the synthesis of water oxidation catalyst, including $\mathrm{Ru},{ }^{11-24} \mathrm{Ir}^{25-26} \mathrm{Fe},{ }^{27-31} \mathrm{Co},{ }^{32-34} \mathrm{Ni}, 35-37$ and $\mathrm{Cu}^{38-40}$

Recently, the Llobet group disclosed the synthesis of a heterotrinuclear Ru2Mn complex $\mathbf{A}_{0}\left\{\left[\mathrm{Ru}^{\mathrm{II}}(\operatorname{trpy})\right]_{2}\left(\mu-\left[\mathrm{Mn}^{\mathrm{II}}(\mathrm{bpp})_{2}\right]\right)(\mathrm{OAc})_{2}\right\}^{2+}{ }^{21}$ This pre-catalyst undergoes water/acetate ligand exchange to form complex $\mathbf{A}\left\{\left[\mathrm{Ru}^{\mathrm{II}}\left(\mathrm{H}_{2} \mathrm{O}\right)(\operatorname{trpy})\right]_{2}\left(\mu-\left[\mathrm{Mn}^{\mathrm{II}}\right.\right.\right.$ $\left.\left.\left.\left(\mathrm{H}_{2} \mathrm{O}\right)_{2}(\mathrm{bpp})_{2}\right]\right)\right\}^{4+}$ (Figure $\mathbf{1}$ ) that is capable of mediating water oxidation both electrochemically and photochemically. ${ }^{41}$ The photochemical reaction was performed using $\left[\mathrm{Ru}(\text { bpy })_{3}\right]^{2+}$ as the photosensitizer and $\mathrm{Na}_{2} \mathrm{~S}_{2} \mathrm{O}_{8}$ as the sacrificial electron acceptor in neutral phosphate buffer. A turnover number of 8 was obtained in about 10 minutes. For the electrochemical reaction, the differential pulse voltammetry (DPV) study of A displayed a catalytic onset potential of $1.5 \mathrm{~V} .{ }^{41}$ A related CoRu2 complex was also reported, and the TON was estimated to be 50 using the same photochemical water oxidation condition. Since the complex water oxidation process involves the removal of four protons and four electrons, this trinuclear complex represents an elegant example that the multiple redox-active metal centers can cooperate during the four electron transfer processes. In addition, all three metals possess one or two aqua ligands. As a consequence, the high oxidation states can be accessed more easily via proton-coupled electron transfer.

To improve the efficiency of water oxidation catalysts and design new catalysts, a detailed mechanistic understanding of the reaction mechanism is of great importance. In recent years, quantum chemical calculations have been successfully applied to 
elucidate the catalytic mechanism for a large number of homogeneous water oxidation catalysts. ${ }^{42}$ In this paper, we carried out quantum chemical calculations to delineate the mechanism of water oxidation catalyzed by this trinuclear $\mathrm{Ru}_{2} \mathrm{Mn}$ complex. Various possible 0-O bond formation pathways have been considered and compared. This study provides a particular opportunity for understanding how three transition metal centers cooperate in water oxidation.

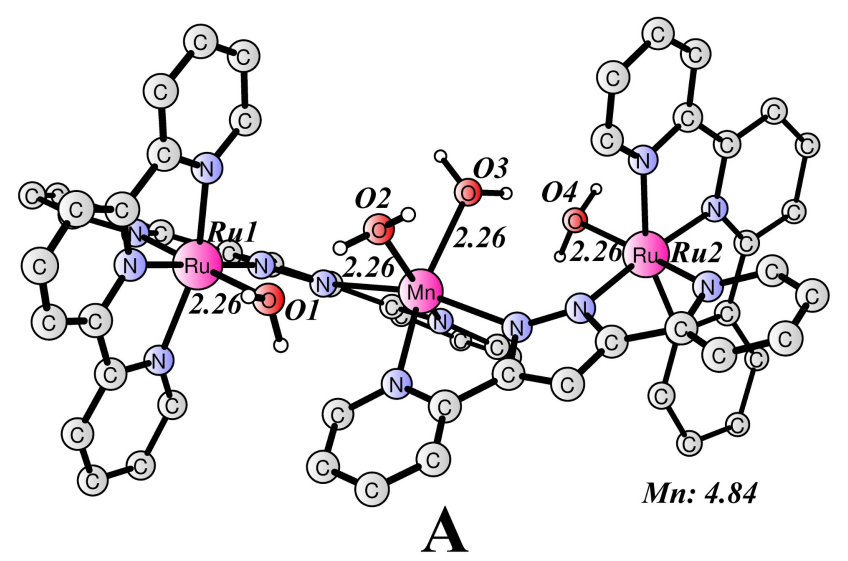

Figure 1. Optimized structures of the trinuclear $\mathrm{Ru}^{I I} \mathrm{Mn}^{I I}$ complex (A, sextet). Distances are given in $\AA$. Spin densities for selected atoms are indicated in italics. Unimportant hydrogen atoms are not shown for clarity.

\section{Computational details}

The quantum chemical calculations were performed using the Gaussian 09 program package. ${ }^{43}$ All geometries were optimized with the B3LYP-D3 functional (including Grimme's D3 dispersion) ${ }^{44,45}$ in combination with the SDD ${ }^{46}$ pseudopotential for $\mathrm{Ru}$ and $\mathrm{Mn}$ as well as 6-31G $(d, p)$ basis set for the $\mathrm{C}, \mathrm{H}, \mathrm{O}$ and $\mathrm{N}$ elements. The final and the solvation energies in water solution were obtained by performing single-point calculations on the optimized geometries using the SMD ${ }^{47}$ continuum solvation model at the B3LYP*-D3 (with 15\% Hartree-Fock exchange, including D3 dispersion and Gibbs free energy corrections from B3LYP-D3) ${ }^{48}$ level with a larger basis set, where $6-311+\mathrm{G}(2 d f, 2 p)$ were used for all atoms except for Ru and Mn (SDD). The harmonic frequencies were computed to characterize the nature of various stationary points as either minima or transition states, and also to obtain the Gibbs free energy 
corrections. Singlet-point calculations were performed at the B3LYP-D3, ${ }^{45}$ M06-D3, ${ }^{49}$ M06L-D3,50 TPSSh-D3,49 TPSS0-D3(25\% Hartree-Fock exchange using TPSSTPSS and keyword IOp(3/76=0750002500) $),{ }^{51-52}$ and TPSSTPSS-D3 ${ }^{53}$ levels to assess the sensitivities of redox potentials and barriers to the choice of functionals.

The $\mathrm{pK}_{\mathrm{a}}$ values were calculated in order to determine the protonation state of all species at the working $\mathrm{pH}=7$, and the experimental solvation energy of $-264.0 \mathrm{kcal}$ mol- $^{-1}$ of a proton was used ${ }^{54}$ The Gibbs free energy correction of $-6.3 \mathrm{kcal} \mathrm{mol}^{-1}$ derived from the translational entropy of a proton in the gas phase was added. ${ }^{54}$ The experimental solvation free energies of water $\left(-6.3 \mathrm{kcal} \mathrm{mol}^{-1}\right)^{54}$ and acetate $(-77.0$ kcal mol-15 ${ }^{55,56}$ in aqueous solution were used. The calculated solvation free energies of water and acetate are $-7.5 \mathrm{kcal} \mathrm{mol}^{-1}$ and $-69.2 \mathrm{kcal} \mathrm{mol}^{-1}$, respectively. The experimental values for the solvation free energies of water and free anions (chloride) has also been used in our previous study on an iron-catalyzed water oxidation reaction. ${ }^{57}$ Importantly, the use of either the experimental values or the calculated values does not alter any mechanistic conclusion. For all species except water, the concentration correction of $1.9 \mathrm{kcal} \mathrm{mol}^{-1}$ at room temperature in water solution was added, which was derived from the change of the standard state from $1 \mathrm{~atm}(24.5 \mathrm{~L}$

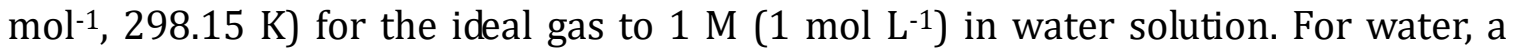
value of $4.3 \mathrm{kcal} \mathrm{mol}^{-1}$ was used as its standard state is $55.6 \mathrm{M}$. For the calculations of the redox potentials, the experimental absolute potential of the $\left[\mathrm{Ru}(\mathrm{bpy})_{2}\right]^{3+} /\left[\mathrm{Ru}(\mathrm{bpy})_{2}\right]^{2+}$ couple $(1.26+4.281 \mathrm{~V})$ was used as a reference, ${ }^{58}$ which corresponds to an electron affinity of $127.8 \mathrm{kcal} \mathrm{mol}^{-1}$. This value was used to set up the free energy diagram for the whole catalytic cycle. This kind of methodology has been documented in details in our recent review ${ }^{42}$ and has been successfully applied to the study of many different molecular water oxidation catalysts. 16, 59-65 


\section{Results and discussion}

\subsection{Redox potentials}

Our investigation starts from the conversion of Ao (Figure S1) to $\mathbf{A}\left(\mathrm{Ru}_{2}{ }^{\mathrm{II}} \mathrm{Mn}^{\mathrm{II}}\right)$ by the displacement of two acetates with four water molecules. This process was calculated to be endergonic by $3.9 \mathrm{kcal} \mathrm{mol}^{-1}$. A was calculated to be a sextet, which has a high-spin $\mathrm{Mn}^{\mathrm{II}}\left(\mathrm{S}_{\mathrm{Mn}}=5 / 2\right)$ and two low-spin $\mathrm{Ru}^{\mathrm{II}}\left(\mathrm{S}_{\mathrm{Ru}}=0\right)$. This is consistent with the EPR and magnetic susceptibility results obtained for $\mathbf{A}_{0}$ in the acetonitrile solution, which showed a six-line signal characteristic of a high-spin $\mathrm{Mn}^{\mathrm{II}}$ ion. ${ }^{41}$ The $\mathrm{pK}_{\mathrm{a}} \mathrm{S}$ of $\mathbf{A}$ and its deprotonated form $\mathbf{A}_{\mathbf{d p}}$ were calculated to be 5.1 and 5.6, respectively. Under the working condition of $\mathrm{pH}=7$, two protons are released from the two $\mathrm{Ru}$-bound water molecules in A to generate A2dp (Figure S1). The formation of A2dp from Ao is thus exergonic by $0.6 \mathrm{kcal} \mathrm{mol}^{-1}$. In A2dp, both Mn-bound water molecules form hydrogen bonds to the two Ru-bound hydroxides.

The one electron oxidation of $\mathbf{A}_{2} d p\left(\mathrm{Ru}_{2}{ }^{\mathrm{II}} \mathrm{Mn}^{\mathrm{II}}\right)$ results in the generation of a septet complex B (Ru1 ${ }^{\mathrm{III}} \mathrm{Mn}^{\mathrm{II}} \mathrm{Ru}{ }^{\mathrm{II}}$, Scheme 1, Figure S1). The spin densities on Ru1 and Mn are 0.83 and 4.82 , respectively. The antiferromagnetic coupled quintet state $(5 \alpha$ on Mn and $1 \beta$ on Ru1) is only $0.2 \mathrm{kcal} \mathrm{mol}^{-1}$ higher in energy. During the oxidation, the electron is removed from one of the two $\mathrm{Ru}^{\mathrm{II}}$ centers, rather than from the $\mathrm{Mn}^{\mathrm{II}}$ center, and the oxidation potential was calculated to be $0.30 \mathrm{~V}$. When the redox potential of the $\left[\mathrm{Ru}(\mathrm{bpy})_{3}\right]^{3+} /\left[\mathrm{Ru}(\mathrm{bpy})_{3}\right]^{2+}$ couple $(1.26 \mathrm{~V}$ vs. SHE) was used as a reference, the formation of complex B is exergonic by $22.1 \mathrm{kcal} \mathrm{mol}^{-1}$. This is followed by the one electron oxidation of the other $\mathrm{Ru}^{\mathrm{II}}$ center with a potential of $0.37 \mathrm{~V}$, leading to the formation of complex $\mathbf{C}\left(\mathrm{Ru} 1^{\mathrm{III}} \mathrm{Mn}^{\mathrm{II}} \mathrm{Ru} 2^{\mathrm{III}}\right.$, Figure $\left.\mathbf{S 1}\right)$. The high spin octet of $\mathbf{C}$ was calculated to be the most stable, and the spin densities on $\mathrm{Ru} 1, \mathrm{Mn}$, and Ru2 are 0.83, 4.85 and 0.83 , respectively. The sextet and quartet states are 3.7 and $0.4 \mathrm{kcal} \mathrm{mol}^{-1}$ higher, respectively. From C, a proton-coupled electron transfer (PCET) oxidation takes place to generate complex $\mathbf{D}\left(\mathrm{Ru} 1^{\mathrm{III}} \mathrm{Mn}^{\mathrm{III}} \mathrm{Ru} 2^{\mathrm{III}}\right.$, Figure $\left.\mathbf{S 1}\right)$, associated with a potential of $0.67 \mathrm{~V}$. During the oxidation, the electron is removed from the $\mathrm{Mn}^{\mathrm{II}}$ center and the proton is removed from the $\mathrm{Mn}^{\mathrm{II}}$-coordinated water molecule. D was 
calculated to be a high-spin septet, and the spin densities on Ru1, Mn, and Ru2 are $0.82,3.90$ and 0.82 , respectively. The quintet and triplet states were calculated to be almost isogonic, being $0.2 \mathrm{kcal} \mathrm{mol}^{-1}$ and $0.5 \mathrm{kcal} \mathrm{mol}^{-1}$, respectively, higher than the septet. From these calculations, it can be seen that in this complex the oxidation of $\mathrm{Mn}^{\mathrm{II}}$ is more difficult than that of $\mathrm{Ru}^{\mathrm{II}}$. The following oxidation also takes place first at the $\mathrm{Ru}^{\mathrm{III}}$ center, rather than the $\mathrm{Mn}^{\mathrm{III}}$ center. The oxidation of $\mathbf{D}$ to generate $\mathbf{1}$ (Ru1 ${ }^{\mathrm{IV}} \mathrm{Mn}{ }^{\mathrm{III}} \mathrm{Ru} 2^{\mathrm{III}}$, Figure 2) was found to be a PCET process, with the proton released from the Ru1-bound hydroxide. The redox potential was calculated to be $0.74 \mathrm{~V} .1$ is an octet, and the spin densities on Ru1, Mn, Ru2 and 04 (Table S1) are 0.81, 3.92, 1.09 and 0.86 , respectively. Consequently, a Ru1 ${ }^{\mathrm{III}}$-oxyl radical is produced. The sextet, quartet and doublet are 11.8, 0.4 and $0.8 \mathrm{kcal} \mathrm{mol}^{-1}$ higher, respectively. In the sextet, an intermediate-spin $\mathrm{Mn}^{\mathrm{III}}(2 \alpha)$ is presented, which makes its energy much higher than the octet state with a high-spin $\mathrm{Mn}^{\mathrm{III}}(4 \alpha)$. Isomerization of $\mathbf{1}$ via proton transfer from the $\mathrm{Mn}^{\mathrm{III}}$ bound water molecule to the Ru1 ${ }^{\mathrm{III}}$-oxyl radical to generate 1' (Ru1 ${ }^{\mathrm{III}} \mathrm{Mn}^{\mathrm{IV}} \mathrm{Ru}^{\mathrm{IIII}}$, Figure $\mathbf{S 3}$ ) with one $\mathrm{Mn}^{\mathrm{IV}}$ center was found to be endergonic by 5.1 kcal mol-1.

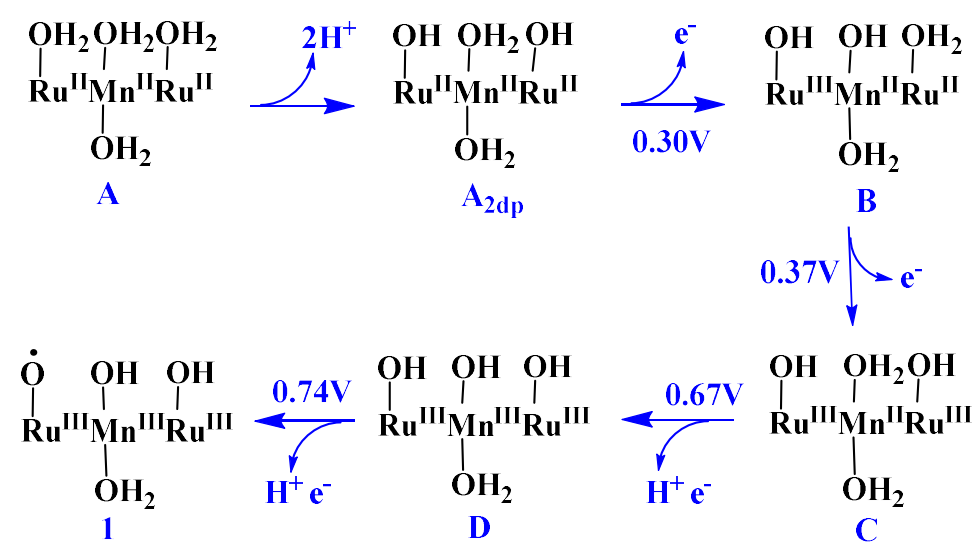

Scheme 1. Conversion of $\boldsymbol{A}$ to $\mathbf{1}$. Other ligands are omitted for clarity.

Complex 1 was found to be the initial species for the whole catalytic cycle (vide infra). The one electron oxidation of $\mathbf{1}$ to form $\mathbf{2}$ (Ru1 ${ }^{\mathrm{IV}} \mathrm{Mn}^{\mathrm{III}} \mathrm{Ru} 2^{\mathrm{IV}}$, Figure 2) is associated with the release of two protons, one from the $\mathrm{Ru} 2^{\mathrm{III}}$ bound hydroxide and the other from the $\mathrm{Mn}^{\mathrm{III}}$ bound water molecule. The $\mathrm{pK}_{\mathrm{a}} \mathrm{S}$ of $\mathbf{2}_{\mathbf{d p t}}$ 
$\left[\mathrm{Ru}^{\mathrm{IV}}(\mathrm{OH}) \mathrm{Mn}^{\mathrm{III}}(\mathrm{OH})_{2} \mathrm{Ru}^{\mathrm{IV}}(\mathrm{OH})\right]^{5+}$ and $\mathbf{2}_{\text {pt }}\left[\mathrm{Ru} 1^{\mathrm{IV}}(\mathrm{O}) \mathrm{Mn}^{\mathrm{IV}}(\mathrm{OH})_{2} \mathrm{Ru} 2^{\mathrm{III}}(\mathrm{OH})\right]^{4+}$ (Figure S3) were calculated to be -1.7 and 6.6, respectively. The redox potential for this oxidation was calculated to be $0.98 \mathrm{~V} .2$ is a nonet, and the spin densities of Ru1, Mn, Ru2, 01 and 04 are 0.97, 3.88, 0.97, 0.97 and 0.97(Table S1), respectively. Therefore, 2 is best described as a high-spin $\mathrm{Mn}^{\mathrm{III}}\left(\mathrm{S}_{\mathrm{Mn}}=2\right)$ ferromagnetically coupled with two low-spin $\mathrm{Ru}^{\mathrm{III}}$-oxyl radicals $\left(\mathrm{S}_{\mathrm{Ru} 1}=\mathrm{S}_{\mathrm{Ru} 2}=1 / 2, \mathrm{~S}_{01}=\mathrm{S}_{04}=1 / 2\right)$. The septet, quintet, triplet and broken-symmetry open-shell singlet states lie at $+17.7,+12.8,+6.9$ and $+1.2 \mathrm{kcal}$ $\mathrm{mol}^{-1}$ higher, respectively. Isomer 2' (Figure S3), with a proton transfer from the $\mathrm{Mn}$ bound hydroxide to one of the oxyl radical in 2 , is $5.8 \mathrm{kcal} \mathrm{mol}^{-1}$ higher than 2 .

Next, in the conversion of $\mathbf{2}$ to $3\left(\mathrm{Ru}_{2}{ }^{\mathrm{IV}} \mathrm{Mn}^{\mathrm{IV}}\right.$, Figure 2$)$, the $\mathrm{Mn}$ is oxidized from $\mathrm{Mn}^{\mathrm{III}}$ to $\mathrm{Mn}^{\mathrm{IV}}$ with a potential of $0.75 \mathrm{~V}$, which is even lower than that of $\mathbf{1}$ to 2 . During the oxidation, no proton is released as the $\mathrm{pKa}_{\mathrm{a}}$ of $3 \mathrm{dp}$ was calculated to be 14.8. $\mathbf{3}$ is an octet, and the spin density on Mn of $\mathbf{3}$ is 2.83. The sextet, quartet and doublet, are 7.6, 12.8 and $7.1 \mathrm{kcal} \mathrm{mol}^{-1}$ higher, respectively. Similarly, with 2 , proton transfer from Mn bound hydroxide to one of the oxyls in $\mathbf{3}$ to generate 3' (Figure S3) is endergonic by $19.5 \mathrm{kcal} \mathrm{mol}^{-1}$.

Then, a PCET of 3 leads to the formation of a Ru1 $1^{\mathrm{IV}} \mathrm{MnV}^{\mathrm{V}} \mathrm{R}^{\mathrm{IV}}$ complex 4 (Figure 2), and the redox potential for this oxidation step was calculated to be $1.54 \mathrm{~V}$. Complex 4 is a septet and the spin densities on Ru1, Mn, Ru2, 01, 02 and 04 are 0.99, 1.05, 2.77, $0.69,-0.53$ and 0.90 , respectively. In $4, \mathrm{Mn}^{\mathrm{IV}}$ is antiferromagnetically coupled with an oxyl radical, which is similar to many other Mn-based water oxidation catalysts, ${ }^{62,66-72}$ including the oxygen evolving complex in photosystem II.66-68 The effect of spin coupling on the energy of $\mathbf{4}$ was calculated using the Noodleman approach (see supporting information for details). ${ }^{73-75}$ The calculated J-value is 3.1 $\mathrm{kcal} / \mathrm{mol}$, and the inclusion of the Noodleman correction decreases the energy by $1.55 \mathrm{kcal} / \mathrm{mol}$, which is very similar to the previous study on the dinuclear Mn water oxidation catalyst. ${ }^{69}$ In this case, a negative spin is presented in this Mn-bound oxyl radical while positive spin in the Ru-bound oxyl radicals. This kind of spin alignment would favor the following 0-0 bond formation by the coupling of two oxyl radicals 
with opposite spin densities. The nonet (with ferromagnetic coupling between $\mathrm{Mn}^{\mathrm{IV}}$ and the oxyl radical), quintet and triplet states are 13.0, 6.4 and $0.5 \mathrm{kcal} \mathrm{mol}^{-1} \mathrm{higher}$, respectively.

The DPV studies of complex A in neutral phosphate buffer gave three oxidation peaks at approximately $0.60,0.74$, and $1.05 \mathrm{~V} .{ }^{41}$ From the present calculations, these three peaks can be assigned as the oxidation of $C$ to $D(0.67 \mathrm{~V})$, the oxidation of $\mathrm{D}$ to 1 $(0.74 \mathrm{~V})$, and the tow electron oxidation of 1 to $3(0.86 \mathrm{~V})$, respectively. Finally, the electrocatalytic wave is observed experimentally at $1.54 \mathrm{~V}$ that is associated with the 3 to 4 oxidation is calculated at $1.54 \mathrm{~V}$. The calculated redox potentials are in very good agreement with the experimentally reported and especially remarkable with the 3 to 4 transition responsible for water oxidation catalysis. The lower oxidation state transitions from $\mathrm{A}$ to $\mathrm{B}$ and $\mathrm{B}$ to $\mathrm{C}$ are not observed experimentally probably due to the low quality of the electrochemical response for this complex. ${ }^{41}$

It is worth mentioning here that the active species, derived from $\mathrm{A}$, that are responsible for the $\mathrm{O}-\mathrm{O}$ bond formation, reach formal oxidation states Ru${ }^{1 \mathrm{~V}} \mathrm{Mn}{ }^{\mathrm{V}} \mathrm{Ru} 2^{\mathrm{IV}}$. This is in good agreement with the OEC-PSII, where a formal $\mathrm{Mn}(\mathrm{V})$ is also needed in the $S_{4}$ state. $66-68$ 


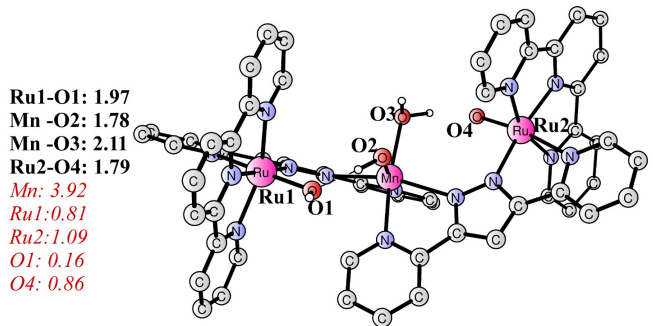

$1 \quad \mathbf{R u 1}{ }^{\mathrm{II}}, \mathbf{M n} \mathbf{n}^{\mathrm{III}}, \mathbf{R u 2} 2^{\mathrm{IV}}$

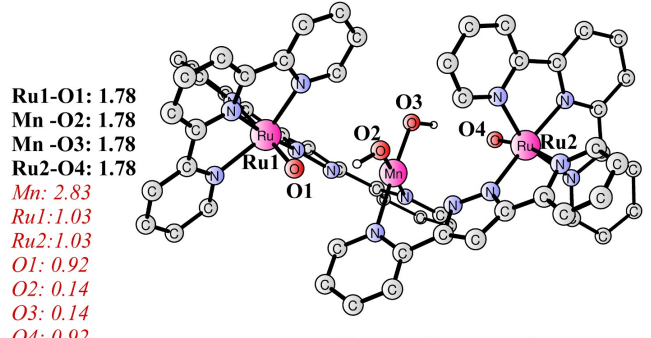

$3 \quad \mathrm{Ru}^{1 \mathrm{iv}}, \mathrm{Mn}^{\mathrm{iv}}, \mathbf{R u} 2^{\mathrm{iv}}$

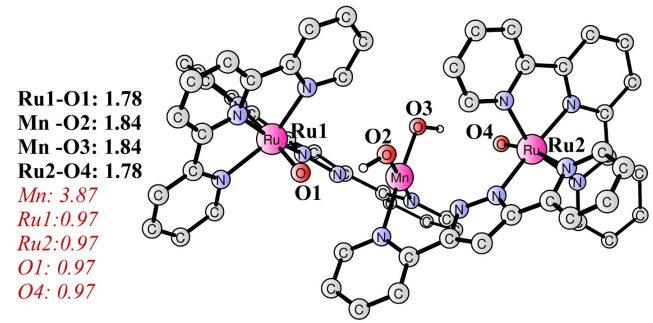

$2 \quad \mathbf{R u 1}^{\mathrm{iv}}, \mathbf{M n} \mathbf{n}^{\mathrm{III}}, \mathbf{R u} 2^{\mathrm{Iv}}$

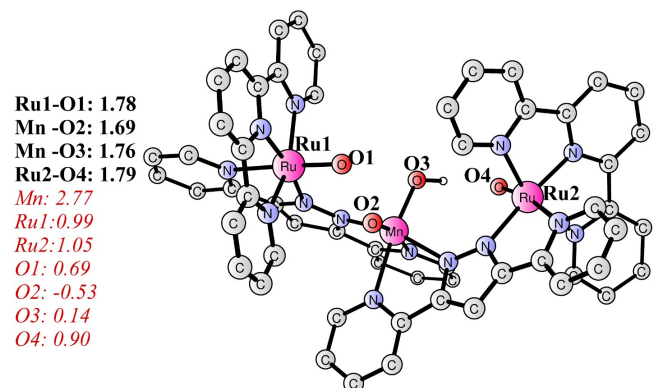

$4 \quad \mathrm{Ru}^{\mathbf{1}^{\mathrm{v}}}, \mathrm{Mn}^{\mathrm{v}}, \mathbf{R u 2} \mathbf{2}^{\mathrm{IV}}$

Figure 2. Optimized structures of 1 (Octet), 2 (Nonet), $\mathbf{3}$ (Octet) and $\mathbf{4}$ (Septet). Distances are given in A. Spin densities on selected atoms are indicated in red italics. Unimportant hydrogen atoms are not shown for clarity. For all structures, only the ground state is shown.

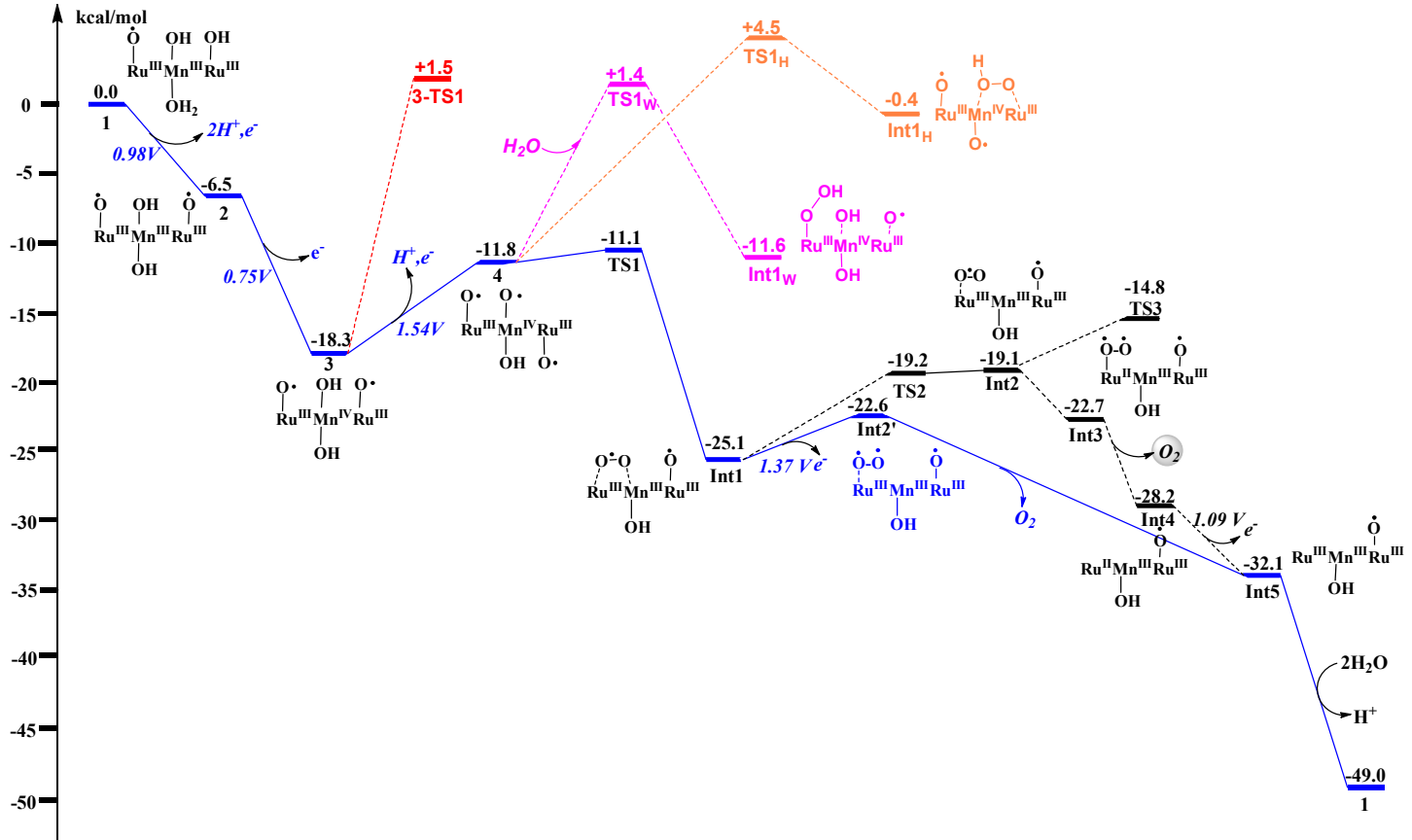

Figure 3. Energy diagram (in $\mathrm{kcal} / \mathrm{mol}$ ) for water oxidation. A reference potential of $1.26 \mathrm{~V}$ was used to set up the diagram. 


\subsection{0-0 bond formation}

O-O bond formation in water oxidation by $\mathrm{Ru}^{17-20,76-80}$ and $\mathrm{Mn}{ }^{62,69-72,81-86}$ catalysts have been widely studied by quantum chemical calculations. The two popular pathways, namely direct coupling (DC) of two adjacent oxygen units and water nucleophilic attack (WNA), were studied herein.

For the direct coupling pathway, we first considered the coupling of two adjacent oxo groups. The transition state (TS1) was optimized and is shown in Figure 4. TS1 prefers to be a septet, and the two oxygen atoms that form the nascent 0-0 bond have opposite spins ( 0.60 on 01 and -0.41 on 02 ). This is required for an efficient 0 0 bond formation, and the important 01-02 distance is $1.89 \AA$ A. TS1 was characterized to be a true transition state with only one imaginary frequency of $136.6 i \mathrm{~cm}^{-1}$. The energy barrier relative to 4 was calculated to be only $0.7 \mathrm{kcal} \mathrm{mol}^{-1}$ (Figure 3), and the total energy barrier became $7.2 \mathrm{kcal} \mathrm{mol}^{-1}$ when the energy penalty for the formation of $\mathbf{4}$ was added. The quintet and triplet barriers were calculated to be 7.2 and $1.1 \mathrm{kcal} \mathrm{mol}^{-1}$, respectively relative to 4 septet. Downhill from TS1, a peroxide intermediate was expected to be formed. However, the calculations showed that an electron is transferred from the peroxide to $\mathrm{Mn}^{\mathrm{IV}}$, which leads to the formation of a superoxide bridging $\mathrm{Mn}^{\mathrm{III}}$ and $\mathrm{Ru} 1^{\mathrm{III}}$. In this intermediate Int1 (Figure 4), the 01-02 distance is $1.32 \AA$, which is shorter than that of a common peroxide 0O single bond (around 1.4 Å). The spin densities are listed as following, Ru1: 0.81, Mn: 3.76, Ru2: 1.03, 01: -0.26, 02: -0.41, 04: 0.92 . Int1 lies at -13.3 kcal mol-1 relative to 4 . The nonet, quintet, triplet and singlet states were calculated to be 3.4, 2.0, 0.3 and 2.8 kcal mol-1 higher in energy, respectively. 

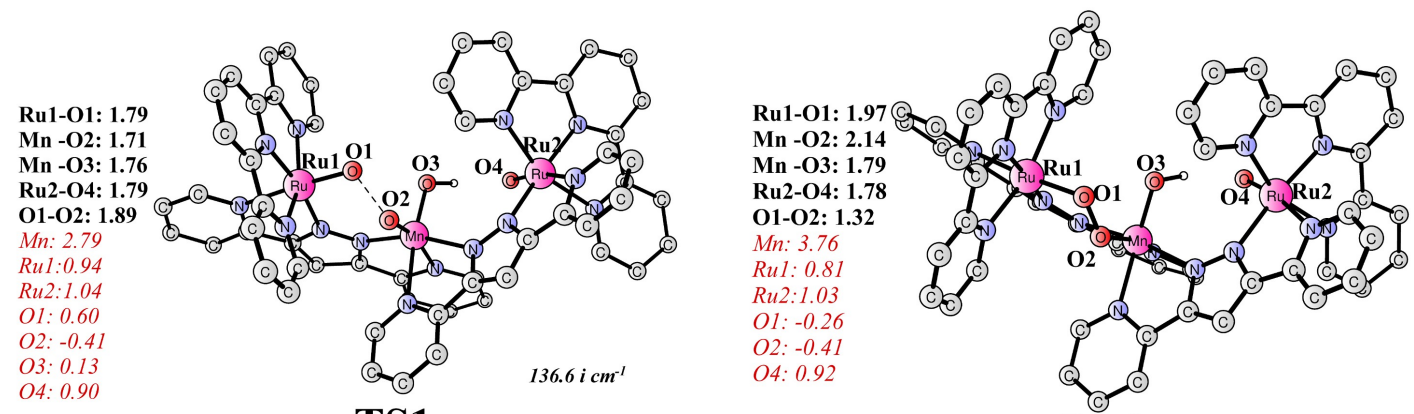

TS1
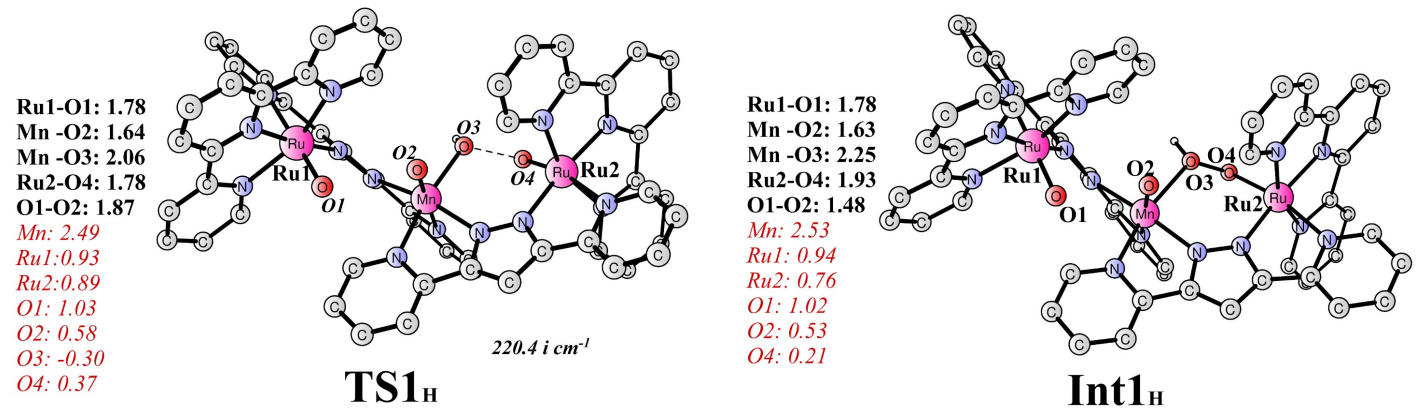

Figure 4. Optimized structures of TS1, Int1, TS1 $\mathbf{H}_{\boldsymbol{H}}$ and Int $_{\boldsymbol{H}}$. All structures are at septet state. Distances are given in Å. Spin densities on selected atoms are indicated in red italics. The imaginary frequencies of transition states are also given. Unimportant hydrogen atoms are not shown for clarity. For all structures, only the ground state is shown.

We then considered the coupling of a Ru2 bound oxyl radical (04) and a $\mathrm{Mn}^{\mathrm{IV}}$ bound hydroxide (TS1н, Figure 4). The barrier of TS1н (septet) was calculated to be +15.6 kcal mol-1 ${ }^{-1}$ igher than TS1, suggesting that this pathway is much less favorable. TS1 $\mathbf{H}_{\mathbf{H}}$ was calculated to be a septet, in which the spin densities on 03 and 04 are -0.30 and 0.37, respectively. In $\mathbf{T S 1}_{\mathrm{H}}$, the important 03-04 distance is $1.87 \AA$ A. This leads to the formation of a hydroperoxide bridging $\mathrm{Mn}^{\mathrm{IV}}$ and Ru2 ${ }^{\mathrm{III}}$ (Int1 $\mathrm{H}$, Figure 4), and this step is endergonic by $11.4 \mathrm{kcal} \mathrm{mol}^{-1}$. Therefore, this pathway is both kinetically and thermodynamically less favorable compared with the coupling of two oxo groups.

For the alternative WNA mechanism, three scenarios were considered, namely attack on one of the two $\mathrm{Ru}^{\mathrm{III}}$-oxyl moieties (TS1w and TS1 ${ }_{\text {wh, }}$ Figure 5) or the $\mathrm{Mn}^{\mathrm{IV}}$ oxyl moiety (TS1w', Figure 5). For TS1w and TS1 w', the proton acceptors are the adjacent $\mathrm{Mn}^{\mathrm{IV}}{ }_{-o x y l}$ and $\mathrm{Ru}^{\mathrm{III}}$-oxyl, respectively. The calculated barrier for TS1 $\mathbf{w}$ is 13.2 kcal mol-1 relative to $\mathbf{4}_{\text {septet }}$ plus a separated water molecule. This is $12.5 \mathrm{kcal} \mathrm{mol}^{-1}$ higher than that of TS1. At TS1w, the critical 01-0w distance is $2.00 \AA \AA$. TS1 w prefers to be an open-shell broken-symmetry singlet, in which the two Ru moieties are 
coupled with the high-spin $\mathrm{Mn}$ in an antiferromagnetic fashion. The triplet, quintet, and septet barriers are 5.7, 0.4, and $0.7 \mathrm{kcal} \mathrm{mol}^{-1}$ higher, respectively. In addition, TS1wh, with the $\mathrm{Mn}^{\mathrm{IV}}$ bound hydroxide as the proton acceptor, is $6.8 \mathrm{kcal} \mathrm{mol}^{-1}$ higher than the TS1w. This suggests that the $\mathrm{Mn}^{\mathrm{IV}}$-bound oxyl group is a better proton acceptor than the $\mathrm{Mn}^{\mathrm{IV}}$-bound hydroxide. (Figure S4) Furthermore, TS1w' lies at +31.3 kcal mol-1 relative to $\mathbf{4}_{\text {septet }}$ plus a water molecule (Figure S4). These calculations suggest that the water nucleophilic attack pathway is not a viable option.
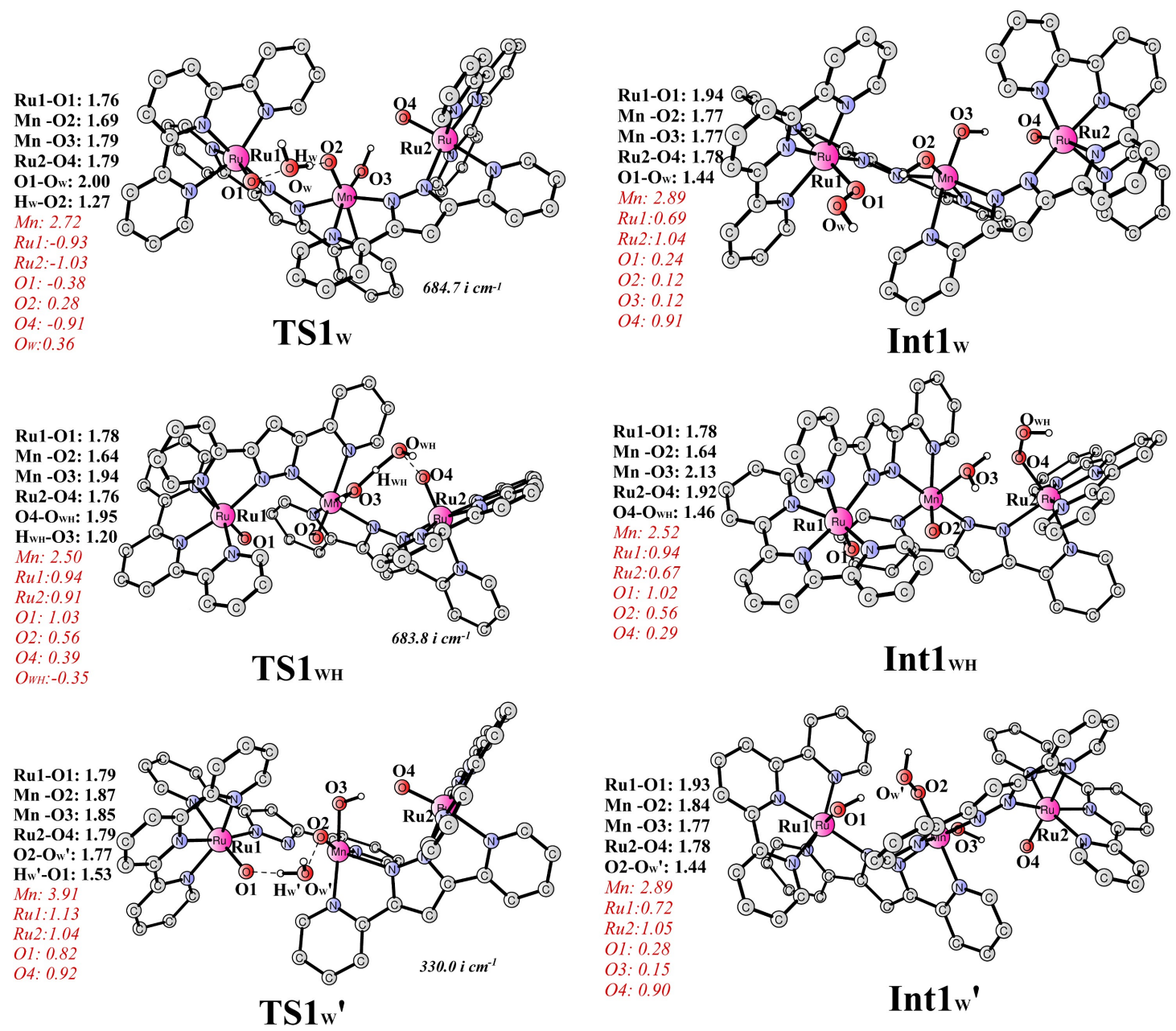

Figure 5. Optimized structures of TS1 $\mathbf{1}_{w}$ (Broken-symmetry Singlet), Int $\mathbf{1}_{w}$ (Septet), TS1 $\mathbf{w}_{\boldsymbol{w H}}$ (Septet), Int1 ${ }_{w \boldsymbol{H}}$ (Septet) $\mathbf{T S 1}_{w^{\prime}}$ (Nonet) and Int1 ${ }_{w}{ }^{\prime}$ (Septet). Distances are given in A. Spin densities on selected atoms are indicated in red italics. The imaginary frequencies of transition state are also given. Unimportant hydrogen atoms are not shown for clarity. For all structures, only the ground state is shown.

O-O bond formation taking place at a lower oxidation state $\mathrm{Ru} 1^{\mathrm{IV}} \mathrm{Mn}^{\mathrm{IV}} \mathrm{Ru} 2^{\mathrm{IV}}$ (3) has 
also been taken into account. The direct coupling of a $\mathrm{Ru}^{\mathrm{III}}$-oxyl moiety and a $\mathrm{Mn}^{\mathrm{IV}}$ bound hydroxide via 3-TS1 (Figure S3) has a barrier of $19.8 \mathrm{kcal} \mathrm{mol}^{-1}$ (Figure 3) relative to 3 . The barrier is thus $12.6 \mathrm{kcal} \mathrm{mol}^{-1}$ higher than that of TS1 as described above. These results further confirmed that $0-0$ bond formation takes place at the formal oxidation state of Ru1 ${ }^{\mathrm{IV} M n V R u 2} 2^{\mathrm{IV}}$.

In addition to the thorough calculated energetic analysis carried out here, the generation of the intramolecular 0-0 bond formation is intuitively supported by the radical nature of all the neighboring $\mathrm{M}-\mathrm{O}$ units at high oxidation states.

\section{$3.3 \mathrm{O}_{2}$ release}

For the release of a triplet $\mathrm{O}_{2}$ molecule from Int1, a number of pathways can be envisioned. First, the superoxide moiety dissociates from the $\mathrm{Mn}^{\mathrm{III}}$ center through a transition state (TS2 in Figure 6). We found that the first dissociation step requires that both the superoxide and the $\mathrm{Mn}^{\mathrm{III}}$ center have positive spin densities. Consequently, the nonet was optimized for TS2, which is shown in Figure 6. The energy barrier was calculated to be $5.9 \mathrm{kcal} \mathrm{mol}^{-1}$ relative to Int1, which is $1.3 \mathrm{kcal}$ mol-1 $^{-1}$ lower (Figure 3) than that of TS1. In TS2, the important Mn-02 distance was calculated to be $2.50 \AA$, and the spin densities on Ru1, Mn, Ru2, 01 and 02 are 0.77 , $3.89,1.03,0.54$ and 0.63 respectively. TS2 was calculated to have only one imaginary frequency of $110.3 i \mathrm{~cm}^{-1}$. In the resulting intermediate Int2 (Figure 6), the Mn-02 distance is $2.63 \AA$ A. In this step, no electron transfer occurs and the superoxide is coordinated to Ru1. Int2 lies at $+6.0 \mathrm{kcal} \mathrm{mol}^{-1}$ relative to Int1. From Int2, partial intramolecular electron transfer from the superoxide moiety to the Ru1 $1^{\mathrm{III}}$ center leads to the formation of the Int3 (Figure 6), which lies at $-3.6 \mathrm{kcal} \mathrm{mol}^{-1}$ relative to Int2. The total spin density on the dioxygen moiety increases from 1.27 in Int2 to 1.59 in Int3. In addition, the 01-02 distance decreases from $1.30 \AA$ in Int2 to $1.25 \AA$ in Int3. The release of a dioxygen molecule from Int3 to form Int4 (Figure 6) is exergonic by $5.5 \mathrm{kcal} \mathrm{mol}^{-1}$. An electronic energy scan by increasing the $\mathrm{Ru}-\mathrm{O}$ distance showed a continuous increase of energy in the gas phase geometry optimization (Figure S5-1). However, transition state can be optimized in the water solution (TS3, Figure S5-2), 
which gave a barrier of only $4.3 \mathrm{kcal} \mathrm{mol}^{-1}$ relative to Int2. Int4 prefers to be a triplet, the septet and quintet are 0.9 and $17.2 \mathrm{kcal} \mathrm{mol}^{-1}$ higher, respectively. In Int4, both $\mathrm{Mn}$ and Ru1 were five-coordinated. Then, one electron oxidation of Int4 results in Int5 (Figure 6), and the electron is removed from the Ru1 ${ }^{\text {II }}$ center with a potential of $1.09 \mathrm{~V}$. In Int5, the spin densities on Ru1, Mn, Ru2 and 04 are 0.72, 3.89, 1.07 and 0.88 , respectively. Int5 is an octet, and the sextet, quartet and doublet state are 0.7 , 6.9 and $1.0 \mathrm{kcal} \mathrm{mol}^{-1}$ higher, respectively. Subsequently, two water molecules bind to the Ru1 ${ }^{\mathrm{III}}$ and $\mathrm{Mn}^{\mathrm{III}}$ centers, coupling with the release of one proton to regenerate $\mathbf{1}$, which can reentry the next catalytic cycle.

An alternative pathway is the one electron oxidation of Int1, leading to the formation of Int2' (Figure 6). The electron is removed from the superoxide moiety, and a triplet $\mathrm{O}_{2}$ is formed in Int2'. The redox potential for this oxidation was calculated to be $1.37 \mathrm{~V}$, which suggests the formation of Int2' is endergonic by 2.5 kcal mol-1 from Int1. Int2' prefers to be dectet, the octet, quartet and doublet state are slightly higher in energies (lying at $+0.6,+0.9$ and $+1.3 \mathrm{kcal} \mathrm{mol}^{-1}$, respectively), while the sextet is $10.1 \mathrm{kcal} \mathrm{mol}^{-1}$ higher. In Int2', the spin densities on Ru1, Mn, Ru2, 01, 02 and 04 are 0.82, 3.90, 1.07, 0.80, 1.01 and 0.89, respectively. The Ru1-01 distance is $2.13 \AA$ A However, geometry optimization in water solution using the SMD solvation model (labeled as Int2P', Figure S6) showed that the triplet $\mathrm{O}_{2}$ dissociates from the Ru1 ${ }^{\text {III }}$ center after the oxidation of Int1, and the Ru1-01 distance increases to 3.01 Å. The release of a triplet $\mathrm{O}_{2}$ molecule from Int2' also leads to Int5. 

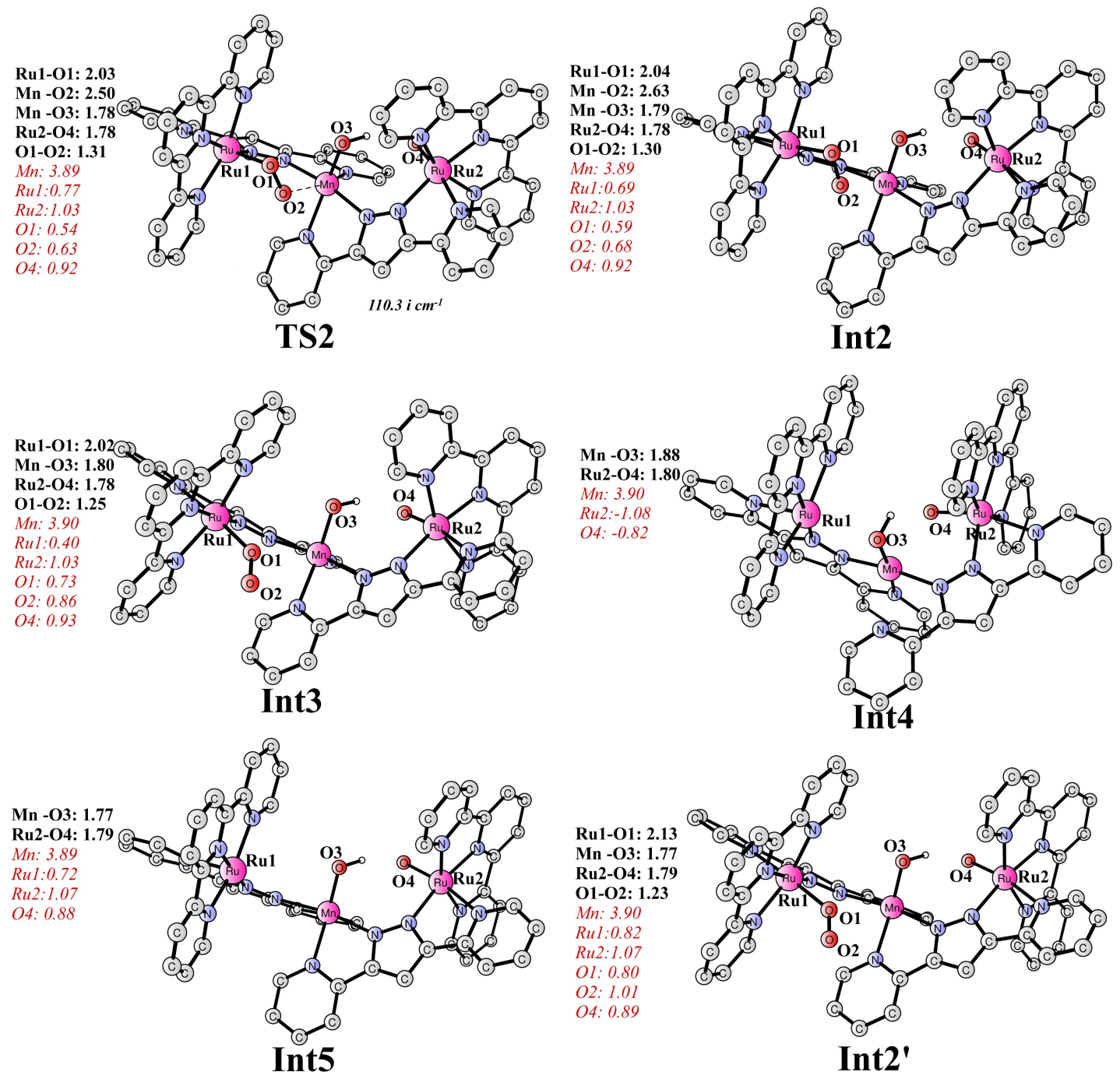

Figure 6. Optimized structures of TS2 (Nonet), Int2 (Nonet), Int3 (Nonet), Int4 (Triplet), Int5 (Octet) and Int2' (Dectet). Distances are given in A. Spin densities on selected atoms are indicated in red italics. Unimportant hydrogen atoms are not shown for clarity. The imaginary frequencies of transition state are also given. For all structures, only the ground state is shown.

The above discussed two pathways may compete with each other. Other possible pathways of $\mathrm{O}_{2}$ release through water insertion into either the $\mathrm{Ru} 1$ center or the $\mathrm{Mn}$ center were found to be energetically less favorable, as discussed in the supporting information (Page S12-S14).

From Figure 3, it can be seen that the calculated total barrier at the B3LYP*-D3 level is only $7.2 \mathrm{kcal} \mathrm{mol}^{-1}$ (from 3 to TS1) assuming that the electrochemical oxidation steps are not rate-limiting. The calculated value is somewhat underestimated compared with the experimental kinetic data (a TON of 12.2 in 10 
minutes; Calculated from Figure 7 in Ref 41), which is about $20 \mathrm{kcal} \mathrm{mol}^{-1}$. This may attribute to the density functional used. Singlet-point calculations at the B3LYP-D3, M06L-D3, M06-D3, TPSS0-D3 (25\% HF exchange), TPSSh-D3 and TPSSTPSS-D3 levels have also been performed to evaluate how sensitive the calculated redox potentials and total barriers are regarding to the choice of the density functionals used. The calculated results are displayed in Table 1. Importantly, all functionals favor the direct coupling pathway for the 0-0 bond formation. The total barrier increases to $11.0 \mathrm{kcal} \mathrm{mol}^{-1}$ when B3LYP-D3 was used, and further to $15.4 \mathrm{kcal} \mathrm{mol}^{-1}$ when M06-D3 was used. The calculated onset potentials at the B3LYP*-D3, M06L-D3 and TPSSh-D3 level are $1.54 \mathrm{~V}, 1.44 \mathrm{~V}$ and $1.51 \mathrm{~V}$, respectively, which are consistent with the experiment results $(1.50 \mathrm{~V}) .{ }^{41}$ However, the B3LYP-D3, M06-D3 and TPSS0-D3 functionals gave slightly higher values. It seems that density functionals with more HF exchange give slight higher values of redox potentials than those with less HF exchange, as found in our previous study on mononuclear iron water oxidation catalyst. ${ }^{57}$ It is also plausible that the oxidation of $\mathbf{3}$ to $\mathbf{4}$ is the rate-limiting step in the photochemical oxidation since the formation of 4 is endergonic by $6.5 \mathrm{kcal} / \mathrm{mol}$. This large endergonicity results in a much slower electronchemical oxidation than the normal exergonic electronchemical oxidation. A stronger oxidant than $\left[\mathrm{Ru}(\mathrm{bpy})_{3}\right]^{3+}$ should favor this step, and lower the total barrier. Indeed, the electrochemical oxidation has a onset potential of $1.50 \mathrm{~V},{ }^{41}$ which is higher than the potential of $\left[R u(b p y)_{3}\right]^{3+} /\left[R u(b p y)_{3}\right]^{2+}$ $(1.26 \mathrm{~V})$.

Table1. Comparsion of the redox potentials and barriers with different functionals.

\begin{tabular}{ccccccc}
\hline & \multicolumn{3}{c}{ Redox Potential(V) } & \multicolumn{3}{c}{ Total Barrier(kcal mol } \\
& $2 / 1$ & $3 / 2$ & $4 / 3$ & $\mathrm{DC}^{-1} \mathrm{o}^{\mathrm{a}}$ & $\mathrm{DC}_{\mathrm{OOH}} \mathrm{b}^{\mathrm{b}}$ & WNA \\
\hline B3LYP*-D3 & 0.98 & 0.75 & 1.54 & 7.2 & 22.8 & 20.2 \\
B3LYP-D3 & 1.13 & 0.97 & 1.70 & 11.0 & 27.0 & 25.2 \\
M06L-D3 & 0.82 & 0.32 & 1.44 & 6.1 & 17.9 & 22.7 \\
M06-D3 & 0.99 & 1.29 & 1.83 & 15.4 & 32.4 & 32.1 \\
TPSS0-D3c & 1.23 & 1.14 & 1.83 & 13.9 & 32.5 & 35.0 \\
TPSSh-D3 & 1.02 & 0.59 & 1.51 & 6.2 & 23.1 & 20.6 \\
TPSSTPSS-D3 & 0.89 & 0.21 & 1.21 & 0.7 & 17.3 & 14.3 \\
\hline
\end{tabular}

a direct oxo-oxo coupling mechanism.

$\mathrm{b}$ direct oxo-hydroxide coupling mechanism.

${ }^{c}$ with $25 \%$ HF exchange. 
Here we used the reorganization energy of $17.2 \mathrm{kcal} / \mathrm{mol}$ and second-order rate constant of $4.2 \times 10^{8} \mathrm{M}^{-1} \mathrm{~s}^{-1}$ for the self-exchange electron transfer between $\left[\mathrm{Ru}(\mathrm{bpy})_{3}\right]^{3+}$ and $\left[\mathrm{Ru}(\mathrm{bpy})_{3}\right]^{2+}$ as a reference, ${ }^{87}$ the barrier $\left(\Delta G^{\neq}\right)$for the oxidation of 3 by $\left[\mathrm{Ru}(\mathrm{bpy})_{3}\right]^{3+}$ was calculated to be $12.7 \mathrm{kcal} / \mathrm{mol}$ using the Marcus theory ${ }^{88}$ by assuming the same reorganization energy for these two different electrochemical reactions.

$$
\Delta G^{\neq}=\frac{\left(\Delta G^{0}+\lambda\right)^{2}}{4 \lambda}
$$

where $\lambda$ is the reorganization energy and $\Delta G^{0}$ is the driving force.

The apparent barrier under the experimental condition $\left(5 \times 10^{-4} \mathrm{M}\right.$ for the concentration of $\left.\left[\mathrm{Ru}(\mathrm{bpy})_{3}\right]^{3+}\right)^{41}$ can be estimated to be $17.2 \mathrm{kcal} / \mathrm{mol}$ when the concentration correction was taken into account. This value can be considered to be in reasonably good agreement with the experimental barrier of about $20 \mathrm{kcal} / \mathrm{mol}^{41}$ The oxidation of $\mathbf{3}$ by $\left[\mathrm{Ru}(\mathrm{bpy})_{3}\right]^{3+}$ may have larger reorganization energy than the self-exchange reaction between $\left[\mathrm{Ru}(\mathrm{bpy})_{3}\right]^{3+}$ and $\left[\mathrm{Ru}(\mathrm{bpy})_{3}\right]^{2+}$. If a reorganization energy of $23.06 \mathrm{kcal} / \mathrm{mol}(1 \mathrm{eV})$ was used, the apparent barrier increases slightly to $18.5 \mathrm{kcal} / \mathrm{mol}$. It should be pointed out that more accurate estimation of the rate for this electrochemical rate for this step requires advanced calculations of reorganization energies (reactant, product, and solvent), driving force, the electronic coupling, and the proton transfer interface properties, ${ }^{89-91}$ which is beyond the scope of the present study.

\section{Conclusion}

In the present work, we have studied the water oxidation mechanism catalyzed by the heterotrinuclear complex $\mathrm{Ru}_{2} \mathrm{Mn}-\left(\mathrm{H}_{2} \mathrm{O}\right)_{4}(\mathbf{A})$ using density functional calculations. The whole catalytic cycle (Scheme 2) including relevant redox intermediates and redox potentials was calculated. 


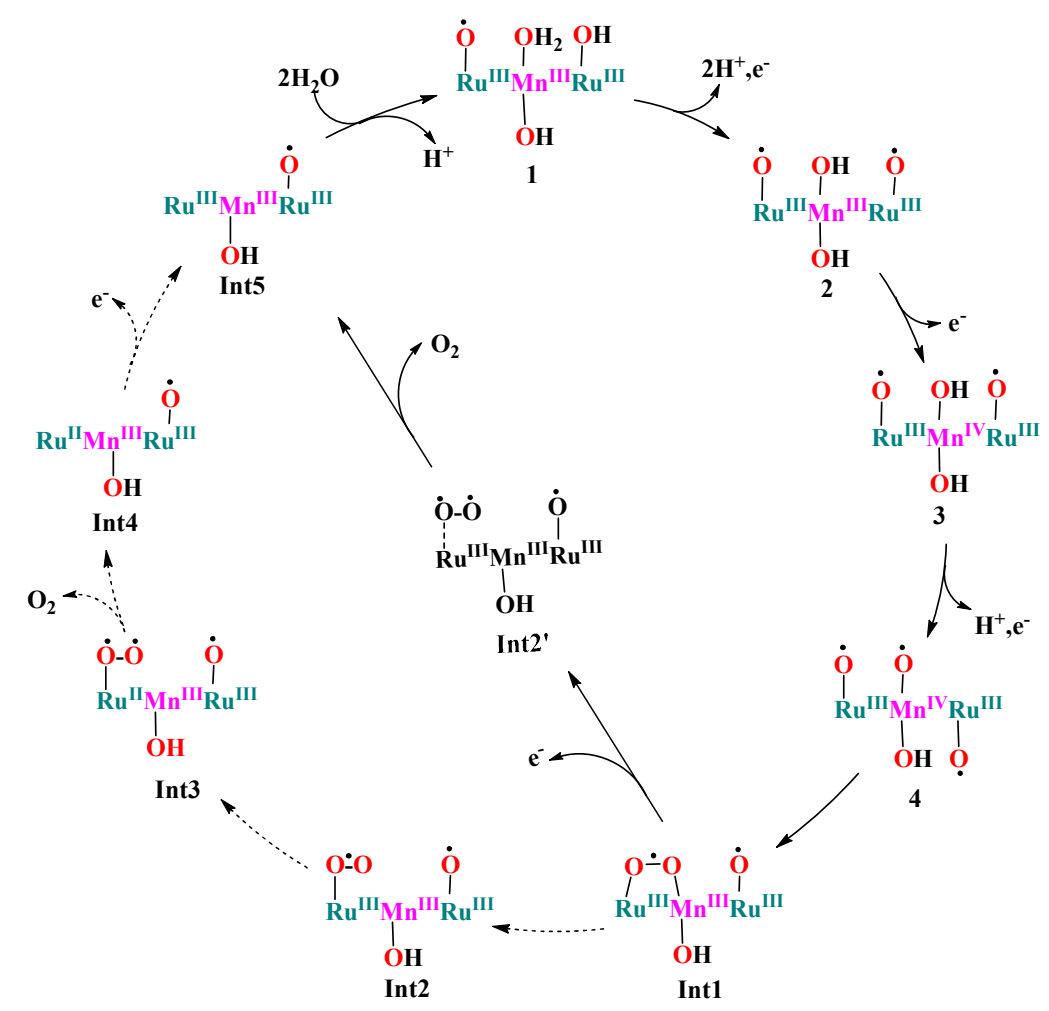

Scheme 2. Suggested catalytic cycle for water oxidation by the heterotrinuclear $\mathrm{Ru}_{2} \mathrm{Mn}$ complex on the basis of calculations.

Water oxidation commences from the formal oxidation state $\mathrm{Ru} 1^{\mathrm{IV}} \mathrm{Mn}^{\mathrm{III}} \mathrm{Ru} 2^{\mathrm{III}}$ (1). A $\mathrm{Ru}^{\mathrm{III}}$-oxyl complex $\mathbf{1}$ was generated from $\mathbf{A}$ through a number of deprotonation and oxidation events. From 1, one electron oxidation of Ru2 leads to $\mathbf{2}$ with a formal oxidation state of Ru $1^{\mathrm{IV} M n^{I I I}}{ }^{\mathrm{Ru}} 2^{\mathrm{IV}}$, and this process is coupled with the release of two protons. Then, one electron oxidation of the $\mathrm{Mn}^{\mathrm{III}}$ center in $\mathbf{2}$ results in $\mathbf{3}$ $\left(\mathrm{Ru} 1^{\mathrm{IV}} \mathrm{Mn}^{\mathrm{IV}} \mathrm{Ru} 2^{\mathrm{IV}}\right)$. Next, a PCET oxidation of $\mathbf{3}$ generates $4\left(\mathrm{Ru} 1^{\mathrm{IV}} \mathrm{Mn}^{\mathrm{IV}} \mathrm{Ru} 2^{\mathrm{IV}}\right)$ with a potential of $1.54 \mathrm{~V}$. Complex 4 is capable of triggering 0-0 bond formation through the direct coupling of a Ru-oxo and a Mn-oxo. The direct coupling of two oxo units leads to the superoxide intermediate Int1, with a total barrier of $7.2 \mathrm{kcal} \mathrm{mol}^{-1}$ at the B3LYP*-D3 level when assuming the electrochemical oxidation of $\mathbf{3}$ is ultrafast. Other 0-O bond formation mechanisms, including the WNA mechanism, the direct coupling of an oxo and a hydroxide, and the direct coupling at a lower oxidation state were calculated to be much less favorable.

The $\mathrm{O}_{2}$ release may take place directly from Int1 or after a one electron oxidation of 
Int1. For the former pathway, the superoxide first dissociates from the Mn center in Int1 via TS2, which generates a Ru1-bound superoxide intermediate Int2. The intramolecular electron transfer from the superoxide to Ru1 leads to the formation of Int3, which has a triplet $\mathrm{O}_{2}$ bound to the Ru1 center. Subsequently, $\mathrm{O}_{2}$ is released, followed by another one electron oxidation to form Int5. Finally, two water molecules bind to Ru1 and Mn, concomitant with a proton release to regenerate $\mathbf{1}$. The one electron oxidation of Int1 results in the direct dissociation of the dioxygen moiety from the Mn center and the formation of a triplet $\mathrm{O}_{2}$ bound to the Ru1 center (Int2').

Int2' can be converted into Int5 after the release of $\mathrm{O}_{2}$. These two pathways about $\mathrm{O}_{2}$ evolution may compete with each other as they were both found to be quite facile. Other possible pathways of $\mathrm{O}_{2}$ release via water insertion are energetically less favorable.

\section{Acknowledgments}

This work was supported by the National Natural Science Foundation of China (21503083 and 21873031) and the Fundamental Research Funds for the Central Universities (2017KFKJXX014). AL thanks support from MINECO, FEDER and AGAUR (CTQ2016-80058-R and 2017-SGR-1631).

\section{References}

[1] Y. Umena, K. Kawakami, J. R. Shen, N. Kamiya, Nature 2011, 473, 55-60.

[2] A. Guskov, J. Kern, A. Gabdulkhakov, M. Broser, A. Zouni, W. Saenger, Nat. Struct. Mol Biol 2009, $16,334-342$.

[3] B. Loll, J. Kern, W. Saenger, A. Zouni, J. Biesiadka, Nature 2005, 438, 1040-1044.

[4] K. N. Ferreira, T. M. Iverson, K. Maghlaoui, J. Barber, S. Iwata, Science 2004, 303, 1831-1838.

[5] M. Suga, F. Akita, M. Sugahara, M. Kubo, Y. Nakajima, T. Nakane, K. Yamashita, Y. Umena, M. Nakabayashi, T. Yamane, T. Nakano, M. Suzuki, T. Masuda, S. Inoue, T. Kimura, T. Nomura, S. Yonekura, L.-J. Yu, T. Sakamoto, T. Motomura, J.-H. Chen, Y. Kato, T. Noguchi, K. Tono, Y. Joti, T. Kameshima, T. Hatsui, E. Nango, R. Tanaka, H. Naitow, Y. Matsuura, A. Yamashita, M. Yamamoto, O. Nureki, M. Yabashi, T. Ishikawa, S. Iwata, J.-R. Shen, Nature 2017, 543, 131-135.

[6] G. Maayan, N. Gluz, G. Christou, Nat. Catal 2018, 1, 48-54.

[7] B. Schwarz, J. Forster, T. Jacob, C. Streb, Angew. Chem. Int. Ed. 2016, 55, 6329 -6333.

[8] C. Zhang, C. Chen, H. Dong, J.-R. Shen, H. Dau, J. Zhao, Science 2015, 348, 690-693.

[9] W. T. Lee, S. B. Munoz, 3rd, D. A. Dickie, J. M. Smith, Angew. Chem. Int. Ed. 2014, 53, 9856-9859.

[10] R. K. Hocking, R. Brimblecombe, L. Y. Chang, A. Singh, M. H. Cheah, C. Glover, W. H. Casey, L. 
Spiccia, Nat. Chem. 2011, 3, 461-466.

[11] D. Wang, S. L. Marquard, L. Troian-Gautier, M. V. Sheridan, B. D. Sherman, Y. Wang, M. S. Eberhart, B. H. Farnum, C. J. Dares, T. J. Meyer, J. Am. Chem. Soc. 2018, 140, 719-726.

[12] R. Matheu, A. Ghaderian, L. Francas, P. Chernev, M. Ertem, J. Benet-Buchholz, V. Batista, M. Haumann, C. Gimbert-Surinach, X. Sala, A. Llobet, Chem. Eur. J., 2018, 24, 12838-12847.

[13] Q. Daniel, L. Duan, B. J. J. Timmer, H. Chen, X. Luo, R. Ambre, Y. Wang, B. Zhang, P. Zhang, L. Wang, F. Li, J. Sun, M. Ahlquist, L. Sun, ACS Catal. 2018, 8, 4375-4382.

[14] F. Cai, W. Su, H. A. Younus, K. Zhou, C. Chen, S. Chaemchuen, F. Verpoort, New J. Chem. 2018, 42, 2476-2482.

[15] L. Francàs, R. Matheu, E. Pastor, A. Reynal, S. Berardi, X. Sala, A. Llobet, J. R. Durrant, ACS Catal 2017, 7, 5142-5150.

[16] S. Zhan, D. Martensson, M. Purg, S. C. L. Kamerlin, M. S. G. Ahlquist, Angew. Chem. Int. Ed. 2017, 56, 6962-6965.

[17] D. W. Shaffer, Y. Xie, J. J. Concepcion, Chem. Soc. Rev. 2017, 46, 6170-6193.

[18] D. W. Shaffer, Y. Xie, D. J. Szalda, J. J. Concepcion, J. Am. Chem. Soc. 2017, 139, 15347-15355.

[19] M. Gil-Sepulcre, M. Bohler, M. Schilling, F. Bozoglian, C. Bachmann, D. Scherrer, T. Fox, B. Spingler, C. Gimbert-Surinach, R. Alberto, R. Bofill, X. Sala, S. Luber, C. J. Richmond, A. Llobet, ChemSusChem 2017, 10, 4517-4525.

[20] T. Fan, L. Duan, P. Huang, H. Chen, Q. Daniel, M. S. G. Ahlquist, L. Sun, ACS Catal 2017, 7, 29562966.

[21] M. Schulze, V. Kunz, P. D. Frischmann, F. Wurthner, Nat. Chem. 2016, 8, 576-583.

[22] Y. Tsubonouchi, S. Lin, A. R. Parent, G. W. Brudvig, K. Sakai, Chem. Commun. 2016, 52, 80188021.

[23] L. Duan, L. Wang, F. Li, F. Li, L. Sun, Acc. Chem. Res. 2015, 48, 2084-2096.

[24] M. D. Karkas, O. Verho, E. V. Johnston, B. Akermark, Chem. Rev. 2014, 114, 11863-12001.

[25] M. Li, S. Bernhard, Catal Today 2017, 290, 19-27.

[26] I. Corbucci, K. Ellingwood, L. Fagiolari, C. Zuccaccia, F. Elisei, P. L. Gentili, A. Macchioni, Catal Today 2017, 290, 10-18.

[27] M. Okamura, M. Kondo, R. Kuga, Y. Kurashige, T. Yanai, S. Hayami, V. K. Praneeth, M. Yoshida, K. Yoneda, S. Kawata, S. Masaoka, Nature 2016, 530, 465-468.

[28] Z. Codola, L. Gomez, S. T. Kleespies, L. Que, Jr., M. Costas, J. Lloret-Fillol, Nat. Commun. 2015, 6, $1-9$.

[29] K. G. Kottrup, S. D'Agostini, P. H. van Langevelde, M. A. Siegler, D. G. H. Hetterscheid, ACS Catal. 2018, 8, 1052-1061.

[30] S. Pattanayak, D. R. Chowdhury, B. Garai, K. K. Singh, A. Paul, B. B. Dhar, S. S. Gupta, Chem. Eur. J. 2017, 23, 3414-3424.

[31] B. Das, B. L. Lee, E. A. Karlsson, T. Akermark, A. Shatskiy, S. Demeshko, R. Z. Liao, T. M. Laine, M. Haukka, E. Zeglio, A. F. Abdel-Magied, P. E. Siegbahn, F. Meyer, M. D. Karkas, E. V. Johnston, E. Nordlander, B. Akermark, Dalton Trans. 2016, 45, 13289-13293.

[32] H. Y. Du, S. C. Chen, X. J. Su, L. Jiao, M. T. Zhang, J. Am. Chem. Soc. 2018, 140, 1557-1565.

[33] T. Ishizuka, A. Watanabe, H. Kotani, D. Hong, K. Satonaka, T. Wada, Y. Shiota, K. Yoshizawa, K. Ohara, K. Yamaguchi, S. Kato, S. Fukuzumi, T. Kojima, Inorg. Chem. 2016, 55, 1154-1164.

[34] L. Xu, H. Lei, Z. Zhang, Z. Yao, J. Li, Z. Yu, R. Cao, Phys. Chem. Chem. Phys. 2017, 19, 9755-9761. [35] L. Wang, L. Duan, R. B. Ambre, Q. Daniel, H. Chen, J. Sun, B. Das, A. Thapper, J. Uhlig, P. Diner, L. Sun, J. Catal 2016, 335, 72-78.

[36] J. Masud, P. Kyritsis, P.-C. Ioannou, N. Levesanos, a. M. Nath, ChemSusChem 2016, 9, 31283132.

[37] M. Zhang, M. T. Zhang, C. Hou, Z. F. Ke, T. B. Lu, Angew. Chem. Int. Ed. 2014, 53, 13042-13048. [38] X. Jiang, J. Li, B. Yang, X. Z. Wei, B. W. Dong, Y. Kao, M. Y. Huang, C. H. Tung, L. Z. Wu, Angew. Chem. 2018, 57, 7850-7854.

[39] K. J. Fisher, K. L. Materna, B. Q. Mercado, R. H. Crabtree, G. W. Brudvig, ACS Catal 2017, 7, 3384-3387. 
[40] X. J. Su, M. Gao, L. Jiao, R. Z. Liao, P. E. Siegbahn, J. P. Cheng, M. T. Zhang, Angew. Chem. Int. Ed. 2015, 54, 4909-4914.

[41] L. Mognon, S. Mandal, C. E. Castillo, J. Fortage, F. Molton, G. Aromí, J. Benet-Buchhlolz, M.-N. Collomb, A. Llobet, Chem. Sci. 2016, 7, 3304-3312.

[42] R.-Z. Liao, P. E. M. Siegbahn, ChemSusChem 2017, 10, 4236-4263.

[43] R. D. Gaussian 09, G. W. T. M. J. Frisch, H. B. Schlegel, G. E. Scuseria, M. A. Robb, J. R. Cheeseman, G. Scalmani, V. Barone, B. Mennucci, G. A. Petersson, H. Nakatsuji, M. Caricato, X. Li, H. P. Hratchian, A. F. Izmaylov, J. Bloino, G. Zheng, J. L. Sonnenberg, M. Hada, M. Ehara, K. Toyota, R. Fukuda, J. Hasegawa, M. Ishida, T. Nakajima, Y. Honda, O. Kitao, H. Nakai, T. Vreven, J. A. Montgomery, Jr., J. E. Peralta, F. Ogliaro, M. Bearpark, J. J. Heyd, E. Brothers, K. N. Kudin, V. N. Staroverov, T. Keith, R. Kobayashi, J. Normand, K. Raghavachari, A. Rendell, J. C. Burant, S. S. Iyengar, J. Tomasi, M. Cossi, N. Rega, J. M. Millam, M. Klene, J. E. Knox, J. B. Cross, V. Bakken, C. Adamo, J. Jaramillo, R. Gomperts, R. E. Stratmann, O. Yazyev, A. J. Austin, R. Cammi, C. Pomelli, J. W. Ochterski, R. L. Martin, K. Morokuma, V. G.Zakrzewski, G. A. Voth, P. Salvador, J. J. Dannenberg, S. Dapprich, A. D. Daniels, O. Farkas, J. B. H.Foresman, J. V. Ortiz, J. Cioslowski, and D. J. Fox, Gaussian, Inc., Wallingford CT, 2013.

[44] S. Grimme,J. Antony, S. Ehrlich, H. Krieg, J. Chem. Phys. 2010,132,154104.

[45] A. D. Becke, J. Chem. Phys. 1993, 98, 5648-5652.

[46] D. Andrae, U. HaiuBermann, M. Dolg, H. Stoll, H. PreuB, Theor. Chim. Acta. 1990, 77, 123-144.

[47] A. V. Marenich, C. J. Cramer, D. G. Truhlar, J. Phys. Chem. B 2009, 113, 6378-6396.

[48] M. Reiher, O. Salomon, B. A. Hess, Theor. Chem. Acc. 2001, 114, 7894-7899.

[49] Y. Zhao, D. G. Truhlar, Theor. Chem. Acc. 2008, 215-241.

[50] Y. Zhao, D. G. Truhlar, J. Chem. Phys. 2006, 125, 194101.

[51] A. Marzouk, B. Madebene, M. E. Alikhani, J. Phys. Chem. A 2013, 117, 4462-4471.

[52] V. N. Staroverov, G. E. Scuseria, J. Tao, J. P. Perdew, J. Chem. Phys. 2003, 119, 12129-12137.

[53] J. Tao, J. P. Perdew, V. N. Staroverov, G. E. Scuseria, Phys. Rev. Lett. 2003, 91, 146401.

[54] D. M. Camaioni, C. A. Schwerdtfeger, J. Phys. Chem. A 2005, 109, 10795-10797.

[55] C. J. Cramer, D. G. Truhlar, J. Am. Chem. Soc. 1991, 113, 8305-8311.

[56] C. P. Kelly, C. J. Cramer, D. G. Truhlar, J. Chem. Theory Comput. 2005, 1, 1133-1152.

[57] Y. Y. Li, L. P. Tong, R. Z. Liao, Inorg. Chem. 2018, 57, 4590-4601.

[58] A. A. Isse, A. Gennaro, J. Phys. Chem. B 2010, 114, 7894-7899.

[59] M. Z. Ertem, L. Gagliardi, C. J. Cramer, Chem. Sci. 2012, 3, 1293-1299.

[60] S. Roeser, F. Bozoglian, C. J. Richmond, A. B. League, M. Z. Ertem, L. Francas, P. Miro, J. BenetBuchholz, C. J. Cramer, A. Llobet, Catal Sci. Technol 2016, 6, 5088-5101.

[61] D. W. Crandell, S. Ghosh, C. P. Berlinguette, M.-H. Baik, ChemSusChem 2015, 8, 844-852.

[62] D. W. Crandell, S. Xu, J. M. Smith, M. H. Baik, Inorg. Chem. 2017, 56, 4436-4446.

[63] I. Funes-Ardoiz, P. Garrido-Barros, A. Llobet, F. Maseras, ACS Catal 2017, 7, 1712-1719.

[64] P. Garrido-Barros, I. Funes-Ardoiz, S. Drouet, J. Benet-Buchholz, F. Maseras, A. Llobet, J. Am. Chem. Soc. 2015, 137, 6758-6761.

[65] R.-Z. Liao, P. E. M. Siegbahn, ACS Catal. 2014, 4, 3937-3949.

[66] P. E. M. Siegbahn, Biochim. Biophys. Acta. 2013, 1827, 1003-1019.

[67] P. E. M. Siegbahn, Acc. Chem. Res. 2009, 42, 1871-1880.

[68] P. E. M. Siegbahn, Chem. Eur. J. 2006, 12, 9217-9227.

[69] M. Lundberg, M. R. A. Blomberg, P. E. M. Siegbahn, Inorg. Chem. 2004, 43, 264-274.

[70] R.-Z. Liao, P. E. M. Siegbahn, J. Catal. 2017, 354, 169-181.

[71] Y. Y. Li, Y. Ke, P. E. M. Siegbahn, R.-Z. Liao, ChemSusChem 2017, 10, 903-911.

[72] R.-Z. Liao, M. D. Karkas, B. L. Lee, B. Akermark, P. E. R. Siegbahn, Inorg. Chem. 2015, 54, 342351.

[73] L. Noodleman, J. Chem. Phys. 1981, 74, 5737-5743.

[74] L. Noodleman, D. A. Case, Adv. Inorg. Chem. 1992, 38, 423-470.

[75] J.-M. Mouesca, J. L. Chen, L. Noodleman, D. Bashford, D. A. Case, J. Am. Chem. Soc. 1994, 116, 11898-11914. 
[76] D. Lebedev, Y. Pineda-Galvan, Y. Tokimaru, A. Fedorov, N. Kaeffer, C. Coperet, Y. Pushkar, J. Am. Chem. Soc. 2018, 140, 451-458.

[77] R. Matheu, M. Z. Ertem, M. Pipelier, J. Lebreton, D. Dubreuil, J. Benet-Buchholz, X. Sala, A. Tessier, A. Llobet, ACS Catal 2018, 8, 2039-2048.

[78] D. W. S. YanXie, Anna Lewandowska-Andralojc,David J. Szalda, and, J. J. Concepcion, Angew. Chem. Int. Ed. 2016, 55, 8067-8071.

[79] R.-Z. Liao, M. D. Kärkäs, T. M. Laine, B. Åkermark, P. E. M. Siegbahn, Catal Sci. Technol 2016, 6, 5031-5041.

[80] X. Sala, S. Maji, R. Bofill, J. Garcia-Anton, L. Escriche, A. Llobet, Acc. Chem. Res. 2014, 47, 504516.

[81] E. M. Sproviero, J. Inorg. Biochem. 2017, 171, 52-66.

[82] P. Xu, T. Zhou, N. Natalia, S. Hu, X. Zheng, J. Phys. Chem. A 2016, 120, 10033-10042.

[83] I. Rivalta, K. R. Yang, G. W. Brudvig, V. S. Batista, ACS Catal. 2015, 5, 2384-2390.

[84] S. Khan, K. R. Yang, M. Z. Ertem, V. S. Batista, G. W. Brudvig, ACS Catal 2015, 5, 7104-7113.

[85] W. M. C. Sameera, C. J.McKenzieb, J. E. McGrady, Dalton Trans. 2011, 40, 3859-3870.

[86] R.-Z. Liao, P. E. M. Siegbahn, J. Photochem. Photobiol B 2015, 152, 162-172.

[87] X. Song, Y. Lei, V. Wallendal, M. W. Perkivic, D. K. Jackman, J. F. Endicott, D. P. Rillema, J. Phys. Chem. 1993, 97, 3225-3236.

[88] R. A. Marcus, Annu. Rev. Phys. Chem. 1964, 15, 155-196.

[89] R. I. Cukier, J. Phys. Chem. 1996, 100, 15428-15443.

[90] S. Hammes-Schiffer, N. Iordanova, Biochim. Biophys. Acta 2004, 1655, 29-36.

[91] S. Hammes-Schiffer, Acc. Chem. Res. 2009, 42, 1881-1889. 


\section{Graphical abstract for}

\section{Quantum Chemical Study of the Mechanism of Water Oxidation Catalyzed by a Heterotrinuclear $\mathrm{Ru}_{2} \mathrm{Mn}$ Complex}

Ying-Ying Lia , Carolina Gimbert ${ }^{\mathrm{b}}$, Antoni Llobet ${ }^{\mathrm{b}}$, Per E. M. Siegbahn ${ }^{\mathrm{c}}$, Rong-Zhen Liao ${ }^{\mathrm{a} *}$

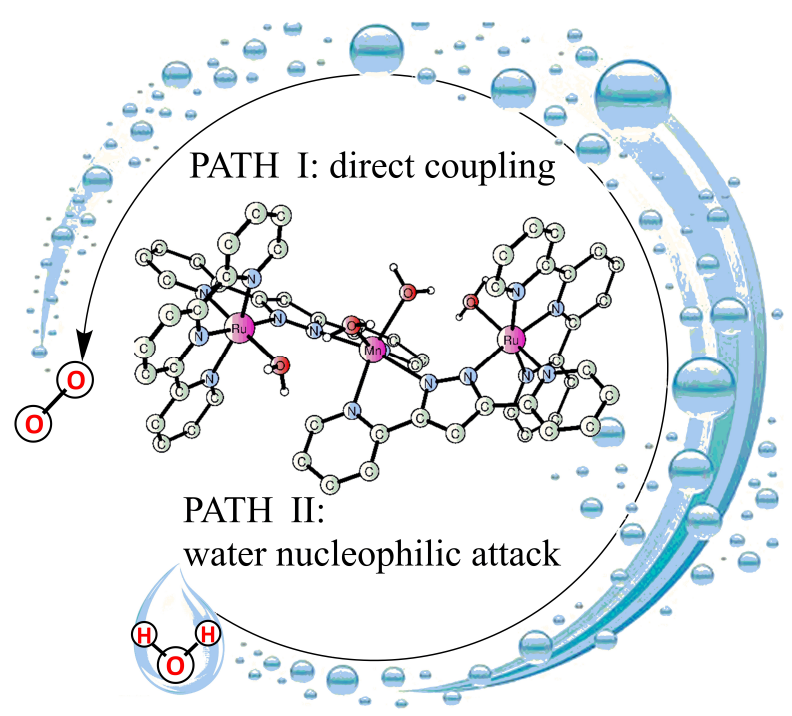

WHICH ONE IS THE LOWER ENERGY?

PATH I OR PATH II? 